\title{
P159: The views of senior hospital managers on innovative strategies to improve hand hygiene adherence: a qualitative study
}

\author{
E McInnes ${ }^{1,2^{*}}$, R Phillips $^{2}$ \\ From 2nd International Conference on Prevention and Infection Control (ICPIC 2013) \\ Geneva, Switzerland. 25-28 June 2013
}

\section{Introduction}

Hand hygiene ( $\mathrm{HH}$ ) adherence remains low among hospital clinicians and improvement strategies such as audit and education have weak or mixed effects. ${ }^{1}$ Innovative approaches are required to improve $\mathrm{HH}$ and reduce hospital-acquired infection rates; hence we sought the views of senior hospital managers about new ways to improve $\mathrm{HH}$.

\section{Objectives}

To identify the views of senior hospital managers on: 1) the concept of $\mathrm{HH}$ non-adherence as a healthcare error; and 2) innovative strategies to include within $\mathrm{HH}$ improvement programs.

\section{Methods}

We conducted a qualitative study at a tertiary referral hospital. Twelve purposively sampled senior clinical and executive staff participated in semi-structured interviews that were audio-recorded and transcribed. Data were thematically analysed.

\section{Results}

Four themes emerged. Making hand hygiene part of the mantra reflects perceptions that $\mathrm{HH}$ culture and practice is variable across disciplines and within different parts of the facility. Shifting the balance of responsibility reflects views that introducing the concept of $\mathrm{HH}$ non-adherence as a healthcare error would strengthen $\mathrm{HH}$ programs. Innovative approaches suggested were: 1) Overdue to start using the hammer: refers to a tiered system of disciplinary action which may include financial fines and suspension from practice for repeated lapses, combined with $\mathrm{HH}$ education as a mandatory part of clinical reaccreditation; and 2) Role modelling and empowering all hospital staff through assertiveness training to remind and prompt each other about $\mathrm{HH}$. This would be supported and sanctioned by hospital policies.

\section{Conclusion}

Basing $\mathrm{HH}$ strategies on the concepts of individual responsibility and non-adherence as a healthcare error was perceived by senior hospital leaders as necessary to reinvigorate and increase the impact of current $\mathrm{HH}$ programs. Future developments will involve evaluating the feasibility of these approaches within $\mathrm{HH}$ improvement programs.

\section{Disclosure of interest}

None declared.

\section{Author details \\ ${ }^{1}$ School of Nursing, Midwifery and Paramedicine, Australian Catholic University, Sydney, Australia. ${ }^{2}$ Nursing Research Institute SVMHS \& ACU, Darlinghurst, Australia.}

\section{Published: 20 June 2013}

\section{Reference}

1. Gould DJ, Moralejo D, Drey N, Chudleigh JH: Interventions to improve hand hygiene compliance in patient care. Cochrane Database of Systematic Reviews 2011, 8, doi: 10.1002/14651858.CD005186.pub3.

doi:10.1186/2047-2994-2-S1-P159

Cite this article as: Mclnnes and Phillips: P159: The views of senior hospital managers on innovative strategies to improve hand hygiene adherence: a qualitative study. Antimicrobial Resistance and Infection Control 2013 2(Suppl 1):P159.

${ }^{1}$ School of Nursing, Midwifery and Paramedicine, Australian Catholic

University, Sydney, Australia

Full list of author information is available at the end of the article

(c) 2013 Mclnnes and Phillips; licensee BioMed Central Ltd. This is an Open Access article distributed under the terms of the Creative 